\title{
Sero-prevalence of Helicobacter pylori Infection in Neyshabur, Iran, During 2010-2015
}

\author{
Mohammad Salehi ${ }^{1,2}$, Abdolmajid Ghasemian ${ }^{3,4}$, Seyyed Khalil Shokouhi Mostafavi ${ }^{5}$, \\ Somayyeh Najafi ${ }^{6}$, Hassan Rajabi Vardanjani ${ }^{7}$
}

1. Medical Diagnostic Laboratory of Neyshabour, Center of Medical, Pathological and Genetic Diagnostic Services, Iranian Academic Center for Education, Culture and Research (ACECR), Mashhad Branch, Mashhad, Iran

2. Research Center for HIV/AIDS, HTLV and Viral Hepatitis, Iranian Academic Center for Education, Culture and Research (ACECR), Khorasan Razavi Branch, Mashhad, Iran

3. Microbiology Department, Faculty of Medicine, AJA University of Medical Sciences, Tehran, Iran

4. Dept. of Bacteriology, Faculty of Medical Sciences, Tarbiat Modares University, Tehran, Iran

5. Dept. of Microbiology, Tehran Medical Sciences Branch, Islamic Azad University, Tehran, Iran

6. Dept. of Microbiology, Faculty of Biological Sciences, Islamic Azad University, Tonekabon Branch, Tonekabon, Iran

7. Researcher of Shahrekord University of Medical Sciences, Shahrekord, Iran

\section{KEYWORDS}

Helicobacterpylori

Seroprevalence

Neyshabur

Enzyme-linked Immuno

Sorbent Assay

Article Info

Received 04 Mar 2016;

Accepted 17 Sep 2016;

Published Online 2017;

\section{ABSTRACT}

Backgrounds \& Objective: The Helicobacter pylori prevalence has continuously decreased during recent years in Iran. The current study aimed at determining $H$. pylori prevalence in Neyshabur city, Northeast Iran, during 20102015.

Methods: The current epidemiologic survey was conducted in Neyshabur from 2010 to 2015 to determine the prevalence of $H$. pylori infection. A total of 11596 participants (3681 male with the mean age of $31.7 \pm 6.2$ years and 7915 female with mean age of $68.3 \pm 4.7$ years) were included. The enzyme-linked immunosorbent assay kits for the detection of $H$. pylori and Stat Fax 3200® Microplate Reader (USA) with a sensitivity of $95 \%$ and specificity of $98 \%$ were used. Titers above 12 units were considered positive for $\operatorname{IgG}, \operatorname{Ig} \mathrm{A}$, and $\operatorname{IgM}$ (negative $<8$, equivocal 8 to 12 , and positive $>12 \mathrm{U}$ ). The Chi-square $t$ test and $\mathrm{F}$ test were used to analyze data.

Results and Conclusion: The overall $\mathrm{IgA}$, IgG, and $\operatorname{IgM}$ seropositive samples among the study participants were $852(7.2 \%), \quad 9000 \quad(72.8 \%), \quad$ and 1256 $(5.2 \%)$, respectively. The IgA seropositivity was significantly high among the age group above 51 years, compared with the other age groups. Moreover, the $\operatorname{IgG}$ and IgM seropositivity were significantly high among the age groups 41 to 50 and 31 to 40 years respectively, compared with the other age groups. There was no significant difference between male and female cases regarding $\operatorname{IgA}$ and $\operatorname{IgG}$ seropositive samples, but IgM level was significantly higher among females, compared with that of the male cases. Furthermore, there was no significant alteration in $\operatorname{IgA}, \operatorname{IgG}$, and $\operatorname{IgM}$ seropositivity during 2010-2014 in Neyshabur. The prevalence of $H$. pylori in Neyshabur was high in the healthy population. Furthermore, the H. pylori prevalence did not change from 2010 to 2014 in the studied city. Effective approaches to improve health, educational, and socioeconomic status should be implemented to minimize and control $H$. pylori infection.

Corresponding Information: Hassan Rajabi Vardanjani, Researcher of Shahrekord University of Medical Sciences, Shahrekord, Iran, E. mail: bacteriology94@gmail.com, Address: Tel: 021-82883862,

Copyright $\odot$ 2017, IRANIAN JOURNAL OF PATHOLOGY. This is an open-access article distributed under the terms of the Creative Commons Attribution-noncommercial 4.0 International License which permits copy and redistribute the material just in noncommercial usages, provided the original work is properly cited. 


\section{Introduction}

Helicobacter pylori (H. pylori) prevalence varies worldwide; however, it remains higher than $50 \%$ in many areas of the world including South America, East Europe and Asia. Helicobacter pylori is associated with gastrointestinal disorders, with important consequences of chronic gastritis, peptic ulcer that leads to gastric cancer, indigestion, and non-ulcer dyspepsia (1). In a review study on the prevalence and risk factors of $H$. pylori infection in the Middle East, it was demonstrated that $H$. pylori infection was high in the region, and in addition, the rate was higher among the patients with dyspepsia, those with histologically confirmed gastritis, and among the older age groups (2). It was determined that the prevalence of $H$. pylori was at the highest level in Turkey and Egypt (>80\%), followed by Iran and Oman (70\% and 80\%, respectively) before 2013. Furthermore, the prevalence of duodenal ulcers, peptic ulcers, and gastritis among cagA+ individuals was 53\% (95\% confidence interval (CI): $20 \%$ to $86 \%$ ), $65 \%$ (95\%CI, $34 \%$ to $97 \%$ ), and $71 \%$ (95\%CI, $59 \%$ to $84 \%$ ), respectively (3). OThe $H$. pylori infection transmission mainly occurs via interpersonal route; however, several other ways are suggested and not clearly explained. On the other hand, the prevalence among younger generations was low (4). A review and meta-analytic study showed that the mean prevalence of $H$. pylori was $50.7 \%$ during 1994- 2011 with the lowest and highest prevalence in Tehran (19.2\%) and Mazandaran (74.27\%) provinces, respectively (5). A survey in Tehran showed that $87.6 \%$ of patients with dyspepsia were infected with $H$. pylori (6). Another study on 14860 consecutive patients with gastritis in Tehran from 2008 to 2014 determined that $83.5 \%$ of the cases were infected with $H$. pylori. In addition, a decline was observed in its prevalence during recent years (7). Several other studies from Asia and Middle East showed that $H$. pylori infection decreased in recent years $(8,9)$. The current study was performed to determine the prevalence of $H$. pylori infection in Neyshabur, Northeast Iran, during 2011-2015.

\section{Materials and Methods \\ Sera samples}

The current epidemiologic, descriptive, cross sectional study was performed in Neyshabur, Northeast Iran, from 2010 to 2015 to determine the prevalence of $H$. pylori infection. A total of 11596 participants referred to the referral laboratory of Mashhad were included and sera samples (a 5-mL blood sample) were prepared and stored at $-20^{\circ} \mathrm{C}$ until use.

\section{ELISA test}

The enzyme-linked immunosorbent assay (ELISA) kits for the detection of H. pylori (Pishtaz teb) and a Stat Fax 3200® Microplate Reader (USA) with the sensitivity of $95 \%$ and specificity of $98 \%$ were used. Any titer above 12 units was considered positive for $\operatorname{IgG}$, IgA, and IgM (negative $<8$, equivocal 8 to 12 , and positive $>12 \mathrm{U}$ ).

\section{Ethical Approval}

The current study protocol was approved by the Research and Technology, Deputy of Iranian Academic Center for Education, Culture, and Research (ACECR), Mashhad Branch.

\section{Data Analysis}

Data were analyzed by SPSS version 20 (IBM SPSS Statistics for Windows, Version 20, Armonk, NY, IBM Corp.); the Chi-square and F tests were employed. P-values $<0.05$ and $\mathrm{F}$ $<0.001$ were considered statistically significant.

\section{Results and Discussion}

Out of 11596 participants, 3681 were male and 7916 female. The mean age of the cases was $45.39 \pm 15.4$ years. Overall, $4500(38.8 \%)$ cases indicated evidence of $\operatorname{IgG}$ seropositivity against H. pylori (ELISA IgG-Ab+), followed by 854 (7.3\%) cases for $\operatorname{IgA}$ and $600(5.2 \%)$ for $\operatorname{IgM}$. The levels of IgG antibody from 2010 to 2015 were $73.6 \%, 67.9 \%, 72.4 \%, 75.6 \%$, and $75.4 \%$, respectively. These levels showed no significant or sensible change during the years of study, using $\mathrm{F}$ test $(\mathrm{Pr}>\mathrm{F}, \quad \mathrm{F}>0.001)$. The $\operatorname{IgA}$ seropositivity was significantly high among the age group above 51 years, compared with the other age groups $(\mathrm{F}<0.001)$. Moreover, the $\mathrm{IgG}$ and IgM seropositivity were significantly high 
among the age groups 41 to 50 and 31 to 40 years, respectively $(\mathrm{F}<0.001)$. There was no significant difference between male and female cases regarding $\operatorname{IgA}$ and $\mathrm{IgG}$ seropositivity, but females had a significantly higher rate for IgM seropositivity, compared with that of the male cases (4.2 vs. $2.5, \mathrm{P}=0.044)$. Furthermore, there was no significant alteration in $\operatorname{IgA}, \operatorname{IgG}$, and IgM seropositivity during 2011-2014 (tables 1 and 2, $\operatorname{Pr}>\mathrm{F}, \mathrm{F}>0.001$ ). Figures 1 and 2 show the level of antibodies and serum level (\%) of antibodies, respectively.

Table 1. The Relationship Between Antibody Titer, Age, and Gender - 2010-2015

\begin{tabular}{|c|c|c|c|c|c|c|c|c|}
\hline \multirow{2}{*}{\multicolumn{2}{|c|}{$\begin{array}{c}\text { Demographic } \\
\text { Features }\end{array}$}} & \multirow{2}{*}{ No. (\%) } & \multicolumn{3}{|c|}{ Seropositivity, N (\%) } & \multirow{3}{*}{$\begin{array}{l}\text { Odds } \\
\text { Ratio }\end{array}$} & \multirow{3}{*}{$\begin{array}{l}\quad 95 \% \mathrm{Cl} \\
\text { Baseline }\end{array}$} & \multirow{3}{*}{ P-value } \\
\hline & & & $\operatorname{Ig} \mathrm{A}$ & $\mathrm{IgG}$ & $\operatorname{IgM}$ & & & \\
\hline \multirow{7}{*}{$\begin{array}{l}\text { Age } \\
\text { group } \\
\text { (year) }\end{array}$} & $0-10$ & $155(1.3)$ & $1(0.6)$ & $30(19.3)$ & $2(1.3)$ & & & \\
\hline & $11-20$ & $912(7.9)$ & $10(1.1)$ & $265(29.1)$ & $43(4.71)$ & 2.119 & $1.321-3.398$ & 0.002 \\
\hline & $21-30$ & $2527(21.8)$ & $85(3.36)$ & 959 (37.9) & $108(4.27)$ & 4.511 & 2.864-7.104 & $<0.0001$ \\
\hline & $31-40$ & $2817(24.3)$ & $140(4.97)$ & $1155(41)$ & $119(4.22)$ & 6.609 & $4.190-10.424$ & $<0.0001$ \\
\hline & $41-50$ & $2435(21)$ & $149(6.1)$ & $1022(42)$ & $93(3.82)$ & 7.263 & $4.589-11.495$ & $<0.0001$ \\
\hline & $51-60$ & $1623(14)$ & $131(8.1)$ & $656(40.4)$ & $53(3.3)$ & 7.33 & $4.582-11.728$ & $<0.0001$ \\
\hline & $61<$ & $1127(9.7)$ & $112(9.9)$ & $413(36.6)$ & $24(2.1)$ & 5.153 & $3.201-8.296$ & $<0.0001$ \\
\hline \multirow{2}{*}{ Gender } & Male & $3681(31.7)$ & $222(6)$ & $1440(39.1)$ & $95(2.5)$ & \multirow{2}{*}{0.982} & \multirow{2}{*}{$0.908-1.062$} & \multirow{2}{*}{0.653} \\
\hline & Female & $7915(68.3)$ & $406(5.13)$ & $3060(38.7)$ & $347(4.4)$ & & & \\
\hline \multicolumn{2}{|l|}{ Total } & $11596(100)$ & $628(5.3)$ & $4500(38.8)$ & $442(7.2)$ & & & \\
\hline
\end{tabular}

Table 2. The Serum Levels of IgG and IgA against Helicobacter pylori During 2011-2014

\begin{tabular}{|c|c|c|c|}
\hline Year & No. & IgG Seropositivity, N (\%) & IgG Seronegativity, N (\%) \\
\hline 2014 & 762 & $575(75.4)$ & $187(24.5)$ \\
\hline 2013 & 1297 & $980(75.6)$ & $317(24.4)$ \\
\hline 2012 & 1195 & $866(72.4)$ & $329(27.5)$ \\
\hline 2011 & 1348 & $916(67.9)$ & $432(32)$ \\
\hline 2010 & 1583 & $1166(73.6)$ & $417(26.3)$ \\
\hline Total & 6185 & $4500(72.8)$ & $1682(27.2)$ \\
\hline
\end{tabular}

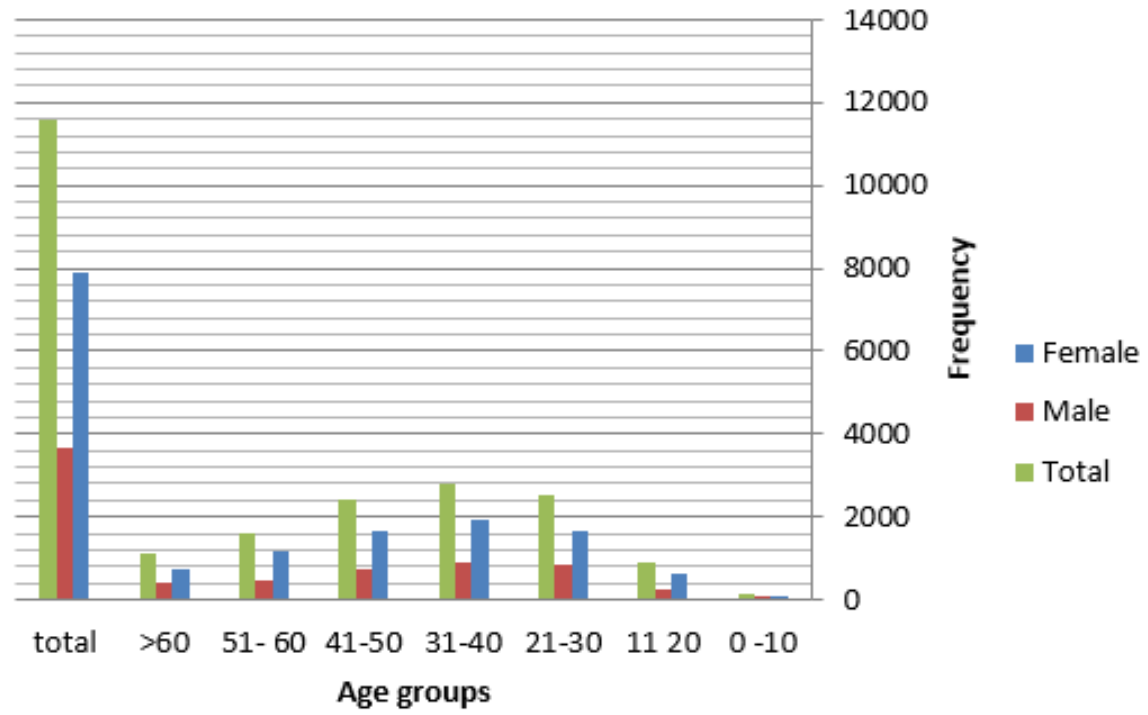

Fig 1. Age-based Distribution of Healthy Individuals in the Study 


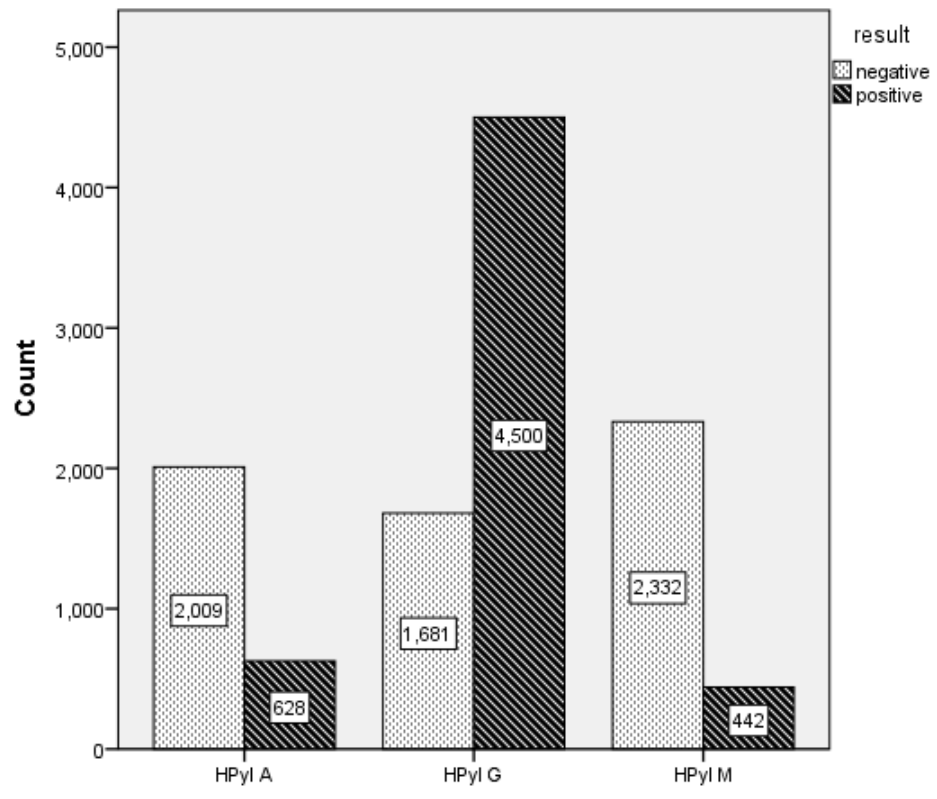

Fig 2. Number of $\operatorname{Ig} \mathrm{A}, \operatorname{IgG}$, and $\operatorname{IgM}$ Seropositive Cases of the Study

It was the first study on $H$. pylori prevalence in Neyshabur, Northeastern Iran. Of the 11596 participants in the current study, 1681 (78.2\%) had the evidence of IgG seropositivity, followed by $854(7.3 \%)$ cases for $\operatorname{IgA}$ and 600 (5.2\%) for IgM seropositivity against $H$. pylori using ELISA kits. The levels of $\mathrm{IgG}$ antibody from 2010 to 2015 were $73.6 \%, 67.9 \%, 72.5 \%, 75.6 \%$, and $75.4 \%$, respectively. These levels showed no significant or sensible change during the years of study. However, most of the previous studies showed that $H$. pylori prevalence gradually decreased in recent years in some areas of Iran and several other countries and that is increased with age $(4,5,10-12)$. A study by Ashtari on 14 860 patients revealed that $83.5 \%$ of the cases were infected with $H$. pylori. Moreover, the prevalence of bacteria in severe gastritis was significantly $(\mathrm{P}<0.05)$ higher than those of mild or moderate statuses. It was concluded that its rate was high among Iranian population, but declined during recent years (7). Moreover, as depicted in Table1, the overall IgA, IgG, and IgM seropositive samples among different age groups of the current study were $442(3.81 \%), 4500$ (38.8\%), and 628 (2.31\%), respectively. The IgA seropositivity was significantly high among the age group above 51 years. Moreover, the IgG and IgM seropositivity were significantly high among the age groups 41 to 50 and 31 to 40 years, respectively. There was no significant difference between male and female cases regarding $\operatorname{IgA}$ and $\operatorname{IgG}$ seropositivity, but females had a significantly higher rate for IgM seropositivity, compared with that of male cases. Furthermore, there was no significant alteration in $\operatorname{Ig} \mathrm{A}, \operatorname{IgG}$, and $\operatorname{IgM}$ seropositivity from 2011 to 2014. In a study by Nouraie on 2561 healthy individuals, the prevalence of $\mathrm{H}$. pylori was $69 \%$ and was correlated with age increase in Tehran province, Iran (13). In another study by Alborzi, in Southern Iran, the prevalence of $H$. pylori were $82 \%, 98 \%, 88 \%, 89 \%$, and $58 \%$ among 9-month, and 2-, 6-, 10-, and 15-year-old cases, respectively, in which there was a significant decrease among the 15-year-old group (14). Moreover, gastric cancer, the most common type of cancer in the North and Northwest Iran, was also highly related to $H$. pylori infection, indicating a high prevalence of $\mathrm{H}$. pylori in these areas (15). In a systematic review and metaanalytic study by Eshraghian, the prevalence of H. pylori ranged from $22 \%$ to $87 \%$ among healthy populations in Iran and the other Eastern Mediterranean region countries (9). In another study by Khedmat, among the Middle Eastern countries, the prevalence of $H$. pylori was high and the rate seemed to be higher among patients with dyspepsia, patients with histologically confirmed gastritis, and also in patients of the elderly groups. Furthermore, Turkey and Egypt showed the highest rate of infection $(>80 \%)$, in Iran and Oman it was $70 \%$ and $80 \%$, respectively (2). On the other hand, it was revealed that the $H$. pylori prevalence was high among less economically advanced and populated countries. Moreover, the intrafamilial transmission may occur. Helicobacter pylori transmission through water showed controversial results (8). In the present study, the relationship of $H$. pylori IgA and $\mathrm{IgG}$ prevalence with age increase of individuals was significant (Table 1), but not for different genders. The rate of $\operatorname{IgA}, \operatorname{IgG}$, and IgM 
seropositivity among the age group 0 to 10 years was $0.6 \%, 19.3 \%$, and $1.3 \%$, respectively, as the lowest level. The highest serum level of antibodies was observed among the age groups $>6,41$ to 50 , and 21 to 30 years old, respectively. Furthermore, the slight alteration in the level of IgG, IgA, and IgM antibodies during 2011-2014 was insignificant.

\section{Conclusion}

The prevalence of $H$. pylori in Neyshabur was high among the healthy population. Furthermore, the $H$. pylori prevalence did not change from 2010 to 2014 in the studied city. These results highlighted the high risk among all of ages groups and possibility of transmission of the disease in this area. $\operatorname{IgA}$ seropositivity was significantly high among the age group above 51 years, while the $\operatorname{IgG}$ and $\operatorname{IgM}$ seropositivity were significantly high among the age groups 41 to 50 and 31to 40 years, respectively. IgM level was significantly higher among females, but not in case of $\operatorname{IgA}$ and $\operatorname{IgG}$. Effective approaches to improve sanitary purposes, and educational and socioeconomic status should be implemented to minimize and control $H$. pylori infection.

\section{Acknowledgments}

The current study was supported by Medical Diagnostic Laboratory of Neyshabur, Center of Medical, Pathological, and Genetic Diagnostic Services, Iranian Academic Center for Education, Culture, and Research (ACECR), Mashhad Branch, Mashhad, Iran.

\section{Conflict of interest}

Authors declared no conflict of interest.

\section{References}

1. van Vliet AH, Kusters JG. Use of alignment-free phylogenetics for rapid genome sequence-based typing of Helicobacter pylori virulence markers and antibiotic susceptibility. J Clinical microbiol. 2015;53(9):2877-88.

2. Khedmat H, Karbasi-Afshar R, Agah $\mathrm{S}$, Taheri S. Helicobacter pylori Infection in the general population: A Middle Eastern perspective. Casp J Intern Med. 2013;4(4):745.

3. Sayehmiri F, Kiani F, Sayehmiri K, Soroush S, Asadollahi K, Alikhani MY, et al. Prevalence of cagA and vacA among Helicobacter pylori-infected patients in Iran: a systematic review and meta-analysis. The J Infect Develop Countr. 2015;9(07):686-96.

4. Eusebi LH, Zagari RM, Bazzoli F. Epidemiology of Helicobacter pylori infection. Helicobacter. 2014;19(s1):1-5.

5. Sayehmiri F, Darvishi Z, Sayehmiri K, Soroush S, Emaneini M, Zarrilli R, et al. A systematic review and meta-analysis study to investigate the prevalence of Helicobacter pylori and the sensitivity of its diagnostic methods in Iran. Iran Red Cres Med J. 2014;16(6).

6. Shokrzadeh L, Baghaei K, Yamaoka Y, Shiota S, Mirsattari D, Porhoseingholi A, et al. Prevalence of Helicobacter pylori infection in dyspeptic patients in Iran. Gastroenterol Insights. 2012;4(1):e8.

7. Ashtari S, Pourhoseingholi MA, Molaei M, Taslimi H, Zali MR. The Prevalence of Helicobacter pylori is decreasing in Iranian patients. Gastroenterology and Hepatol Bed Bench. 2015;8(Supplement).

8. Mentis A, Lehours P, Mégraud F. Epidemiology and Diagnosis of Helicobacter pylori infection. Helicobacter. 2015;20(S1):1-7.

9. Eshraghian A. Epidemiology of Helicobacter pylori infection among the healthy population in Iran and countries of the Eastern Mediterranean Region: A systematic review of prevalence and risk factors. World $\mathbf{J}$ Gastroenterol: WJG. 2014;20(46):17618.

10. Ashtari S, Pourhoseingholi MA, Molaei M, Taslimi H, Zali MR. The prevalence of Helicobacter pylori is decreasing in Iranian patients. Gastroenterol Hepatol Bed Bench. 2015;8(Suppl1):S23.

11. Soltani J, Amirzadeh J, Nahedi S, Shahsavari S. Prevalence of helicobacter pylori 
infection in children, a population-based crosssectional study in west Iran. 2013.

12. Moosazadeh M, Lankarani KB, Afshari M. Meta-analysis of the prevalence of helicobacter pylori infection among children and adults of Iran. Intern J Prevent Med. 2016;7.

13. Nouraie M, Latifi-Navid S, Rezvan H, Radmard AR, Maghsudlu M, Zaer-Rezaii H, et al. Childhood hygienic practice and family education status determine the prevalence of Helicobacter pylori infection in Iran. Helicobacter. 2009;14(1):40-6.

14. Alborzi A, Soltani J, Pourabbas B, Oboodi B, Haghighat M, Hayati M, et al. Prevalence of Helicobacter pylori infection in children (south of Iran). Diagnost Microbiol Infect Dis. 2006;54(4):259-61.

15. Malekzadeh R, Derakhshan $\mathrm{MH}$, Malekzadeh Z. Gastric cancer in Iran: epidemiology and risk factors. Arch Iran Med. 2009;12(6):576-83.

\section{How to Cite This Article:}

Salehi M, Ghasemian A, Shokouhi Mostafavi SK, Najafi S, Rajabi Vardanjani H. Sero-prevalence of Helicobacter pylori Infection in Neyshabur, Iran, during 2010-2015. Iran J Pathol. 2017;12(2):183-188. 